a tolerable degree of accuracy if the patient can be thoroughly examined, and the differential diagnosis between and analogous clinical features constantly borne in mind. Diseases which have many points in common with syringomyelia are anæsthetic leprosy, Morvan's disease, multiple neuritis, hysteria, muscular atrophy and amyotrophic lateral sclerosis. Morvan's disease and anæsthetic leprosy are of such rare occurrence in America that the differential diagnosis need not be considered. Hysteria and multiple neuritia, as a rule, have very few symptoms which could be construed as syringomyelia; exceptional cases of hysteria might for a time simulate syringomyelia, but by close watching and careful examinations the counterfeit will be readily detected. The two affections which offer to the eye an aggregation of symptoms closely resembling syringomyelia are amyotrophic lateral sclerosis, especially in the early stages, and progressive muscular atrophy. The differential diagnosis of these three affections as I have met them, ignoring for the time the text-book descriptions, may be tabulated as follows:

\begin{tabular}{|c|c|c|c|}
\hline & $\begin{array}{l}\text { Iruscular } \\
\text { Atrophy. }\end{array}$ & $\begin{array}{c}\text { Amyotrophic } \\
\text { Lateral } \\
\text { Sclerosis. }\end{array}$ & Syringomyelia. \\
\hline $\begin{array}{l}\text { Age... } \\
\text { Sex . . . . } \\
\text { Onset . } \\
\text { Course } \\
\text { Muscular atrophy. } \\
\text { Taetile sensiblity . } \\
\text { Sense of pain } \\
\text { Temperature sense. } \\
\text { Tendon refexes... }\end{array}$ & $\mid \begin{array}{c}25-35 \\
\text { Male } \\
\text { Gradual : } \\
\text { Progressive } \\
\text { Marked } \\
\text { Intact }: \\
\text { Normal : } \\
\text { Normal : } \\
\text { Diminished } \\
\text { or absent. }\end{array}$ & 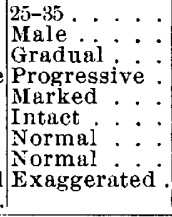 & $\begin{array}{l}25-35 . \\
\text { Male. } \\
\text { Gradual. } \\
\text { Progressive. } \\
\text { Marked. } \\
\text { Intact. } \\
\text { Analgesia. } \\
\text { Thermonnesthesia. } \\
\text { Exaggerated. }\end{array}$ \\
\hline
\end{tabular}

The similarity of these affections is striking, and in diagnosing a case of syringomyelia, the verdict will depend upon the stage of the examination, as progressive muscular atrophy, amyotrophic lateral sclerosis or syringomyelia.

LITERA TURE.

Gazette des Hopitaux, December 7, 1889

Archiv, Gen. de Med, July 1, 1889.
Deutsch. Archiv, f. Kitn. Med., B. xl, p. $443,1886$.

Amer. Journal of Medical Sciences, May, 1888, p. 457.

New York Med. Jourual, 1889, p. $2 \% 8$

Journul of Nervous and Mentil Disease, July, 1889, p. 393.

New York MIedicnl Record, 1888, p. 23i.

Jour. of Nervous and Mental Disease. September, 1890, p. 568.

N. Y. Medical Record, December 12, 1891, p. 704.

N, Y. Medical Journal, 1890, Vol. 1i, p. 613 .

\section{A CASE OF TRANSITORY MANIA WITH PECULIAR SEQUELAE.}

Read in the Section of Neurology and Medical Jurisprudence at the Forty-third Anuual Meeting of the American Medical Association, held at Detroit, Mich., June, 1892.

BY G. R. TROWBRIDGE, A.M., M.D.,

Fellow o' the American Aeademy of Medicine; Member of the American Medical Association, and N. Y. Medico-Legal Society; 2nd Pennsylvania.

The following case was one that proved of especial interest to me, for the reason that $I$ was very much puzzled as to what conditions existed to cause such a sudden and peculiar attack and the consequent train of signs and symptoms. Whether or not my title is a misnomer I do not know, and at all events it is of little importance. I shall give as full and detailed an account of the case as possible for I intend to do nothing more, but leave the comments and diagnosis to others.

Mrs. K., female; aged 47 years ; married and has six children. Admitted to this hospital February 17, 1892

Physically is a short. slight woman, $5 \mathrm{ft} .2 \mathrm{in}$. in height; weight between 90 and $100 \mathrm{lbs}$; dark hair and eyes; very nervous temperament. Apparently has no organic disease. The history of the case before admission is as follows: About two weeks before coming to the hospital the patient retired at night feeling as well as usual, and slept q ietly until about 3 o'clock in the morning, when she was awakened by a most intense pain in the lumbar region of the spinal column, which extended rapidly upward until it reached the base of the brain and then, as she described it "it seemed to me as if my head was splitting into a thousand pieces, and that some terrible pressure on the inside was doing it." She had scarcely time to tell her husband to go quickly for a physician, before she sank into a condition of complete unconsciousness. This increased until the woman was in an almost comatose condition; pulse between 35 and 40 , respiration slow and shallow; extremities cold and body covered with a profuse, cold perspiration. With proper treatment and care she regained consciousness, and was in fairly good condition physically though greatly prostrated by the attack. In a few days abnormal mental symptoms presented themselves and she developed a number of unsystematized delusions and moreover became almost unmanageable. She conceived the idea that the neighbors in returning from an evening company came to her house bringing mattrasses and bedding with them and slept all night on the floor of her bedroom. She also showed unmistakable homicidal tendencies toward her husband and nurse and moreover endeavored to set fire to the house by upsetting a lamp. Her bodily condition all this time was considerably impaired. Such is the history of the case before her admission to the hospital. She was brought here under the impression that she was going to procure a divorce from her husband, for ill-treatment. On my first examination I found her very weak, and unable to walk or even stand alone, and this inability I ascribed at first to her apparent bodily weakness. Bowels were sluggish; appetite poor; pulse weak and over a hundred. She was rather reticent at first and would talk very little. She was put on tonic treatment and nourishing diet. The bowels were kept free by enemata, as laxative and cathartic remedies were of no avail. This fact first attracted my attention when I learned that there was no evidence of special constipation or accumulation, but there was an utter lack of power to empty the rectum. I afterwards learned that this had been the condition since the night she was taken ill. There was no difficulty in urination. After a residence in the hospital of about five days she became more communicative, and told me considerable about her illness and that she had been in the hospital five weeks. She did not, however, mention her delusions. I made up my mind that her inability to walk alone was not due to bodily weakness but to a paralysis of the lower extremities due to some disturbance in the brain or cord. She complained of "cold feet," and yet there was no indication of this being so. The sensation was apparently normal and the patellar reflex was somewhat increased. At this time she showed a cross and irritable disposition, and though in our convalescent ward complained most bitterly of her surroundings, food, clothes, etc., etc., and of being "Iocked up with a lot of crazy people."

On the morning of March 15, 1892, I found my patient in bed, and she told me she had had another slight attack of the "same pain" she had the night she was first taken ill. She was considerably worried over it, fearing she would be "very ill and this time die." Seeing a good opportunity I asked her to tell me about the attack which she had had at home which she did very accurately, her story corresponding very closely with the history I have given, except she remembered nothing for several days after the attack, and her last remembrance of anything was requesting her husband to go for the doctor. In spite of this statement, however, she remembered her delusions when they were suggested to her, and though her enmity toward her husband had diminished somewhat, she still had the delusion in regard to the neighbors sleeping on the floor of her bed-room, though she did not remember this as developing until sometime after the attack. In other words, though she recovered consciousness soon after her attack, there is a blank of several days which she cannot account for, and yet her condition was one of only an apparent attack of acute mania, as during her excitement she did things which showed she was conscious of her surroundings. She improved considerably both physically and mentally, but at the time of her discharge still clung to her strange delusion regarding her neighbors. Her husband came for her at the time she was discharged and she showed no hostility toward him. I have heard since her discharge that she is improving rapidly as I expected, for at the time she left the hospital she was 
rapidly gaining the use of her limbs. Such is the case in full as far as I can give it and I shall leave it without diagnosis or comments, but I have regarded it as interesting for the following reasons :

1. The sudden advent of the attack.

2. The comatose condition following it.

3. The peculiar groundless but apparently fixed delusion.

4. The paralysis of the lower extremities and inability to evacuate the bowels.

Was there a lesion? If so, what was it, and where was it?

ADDRESS OF THE CHAIRMAN.-RESPONSIBIIITY OF THE NATIONAL AND STATE GOVERNMENTS FOR THE PROTECTION OF THE PURITY OF THE WATER SUPPLIES.

Delivered before the Section of State Medicine at the Forty-third Annual Meeting of the American Medical Association. held at Detroit, Mich.. June, 1892.

BY BENJAMIN LEE, M.D., OF PHILADELPHIA.

Before entering upon the consideration of the question announced as the subject of my address, to which I shall ask your attention for but a few moments, it seems fitting that a brief allusion should be made to the question of the re-organization of the parent asssociation of which this body is one of the members, in the interest of scientific work as contrasted with the transaction of routine business and the reading of essays on abstract subjects. No one who has attended the meetings of the Association with any degree of regularity for the past ten years can have failed to observe the growing importance of the Sections and the hold which they have on the interest of the members. To such an extent is this is true that a writer in the American Lancet has not hesitated to formulate the terse phrase "The Sections are the Association." If this be admitted the step is an easy one to the further assertion, "The Sections should control the Association." The chairman of the Section of Ophthalmology at the meeting of the last year devoted his address to indicating in what way the Sections might "control the Association," and courteously sent a copy of his address to the chair man of this and, it is presumed, of every other Section, if not to all the members of the Association. At the last meeting of this Section a committee of three was appointed to confer with similar committees to be appointed by the other Sections, to take up the whole subject of the development of the Sections. A place has been given in the program for the report of this committee and an opportunity will then be presented for full discussion of this important movement.

The proposal of the Chairman of the Ophthalmological Section would, as it seems to me, to a great extent do away with the Judicial Council as at presentconstituted, as also with the Nominating Committee, and place all the business now discharged by those bodies in the hands of a council composed of ex-chairmen of Sections for the three preceding years.

It is claimed that this plan would give the smaller Sections an equal representation in the general administration of the affairs of the Association with the larger Sections, and that the members of such a council would be thoroughly familiar with the needs and interests of the Sections. This would practically put an end to the system of geographical repre- sentation which has heretofore been warmly cherished by a large portion of the Association, and which they may feel loath to abandon. While seeing much in the scheme to approve, two objections occur to me which I feel are entitled to consideration. First, the work of the Judicial Council is often large in amount and exacting in character. The ex-chairmen of a Section are apt to be earnest workers in the Section and contributors to its program and discussions. If this labor is assigned to them, is it not possible that it may prove so engrossing as to take them away from the Section sessions, and thus diminish the interest of the latter? Secondly, eight out of the eleven Sections are composed of men who are more or less strictly specialists. Of course it is gratifying and instructive to them to meet those who are following the same lines of work, to become acquainted with them personally, to exchange ideas with them, and profit mutually by one another's experiences, efforts and discoveries. But, if only such as are thus bound together by ties of business interest, and it must be confessed after all that Section work has its business aspect to a very considerable degree, are to meet one another, listen to one another, talk to one another and eat and drink with one another, will not the effect be to increase the narrowness of the professional and intellectual horizon, which their daily routine necessarily involves, instead of broadening the view and widening the field of thought, as one would like to feel to be the result of annual association with the great minds of every branch of the profession. For this latter reason the proposal that each Section should have a stated social gathering of its own should not be too hastily adopted. The idea of having the procedings and papers of each Section reprinted from The Journal of the Association on fine paper with cloth binding would probably entail greater expense on each individual member in a small Section like ours than in a large one. It is, however, well worthy the attention of the members. And just here it may not be out of place to advert briefly to a disadvantage under which our Section labors. Nearly all its members are engaged in the active practice of medicine or surgery. The work which they do here and the time which they bestow, contribute in no way to their knowledge of the particular department of medical science or art to which they devote themselves and on which they depend for a livelihood. They know that in many other Sections papers are being read which would convey to them information of inestimable value, and discussions participated in by men to whom their ears are burning to listen. They are with us, therefore, at no trifling personal self-sacrifice. Hence, it can never be otherwise but that attendance on our sessions should be limited in members and fluctuating in character. Would it not be well to accept this fact and govern ourselves accordingly?

This thought has been in the minds of the officers in arranging the program of the present meeting, certain available periods having had no session assigned them, in order to allow the opportunity for attendance on these of other Sections.

GOVERNMENTAL RESPONSIBILITY FOR THE PROTECTION OF WATER SUPPLIES.

The question of the pollution of streams and other sources of water supply on this continent is rapidly assuming the greatest gravity. It is curious to notice 